Research Article

\title{
Lipid lowering and antioxidant potential of Asparagus racemosus in hyperlipidemic rats
}

\author{
Rama R. Bhosale", Jugalkishor B. Jaju, Sudhir L. Padwal, Rakesh R. Jadhav, \\ Vinod S. Deshmukh
}

Department of Pharmacology,

Swami Ramanand Teerth Rural

Govt. Medical College,

Ambajogai, District- Beed,

Maharashtra 431517, India

Received: 1 October 2012

Revised: 15 October 2012

Accepted: 17 October 2012

*Correspondence to:

Dr. Rama R. Bhosale,

Email:

bhosale.rama@rediffmail.com

\begin{abstract}
Background: Atherosclerosis is associated with hyperlipidemia which is a major risk factor for coronary artery disease. Therefore, treatment of hyperlipidemia is one of the major approaches to decrease the atherogenic process. Many studies revealed that Asparagus racemosus (AR) possesses hypolipidemic and antioxidant potential, but results were not consistent. Therefore, the present study was undertaken to investigate lipid lowering and antioxidant potential of AR root powder in hyperlipidemic rats.
\end{abstract}

Methods: Hyperlipidemia was induced in normal rats by including $0.75 \mathrm{gm} \%$ cholesterol and $1.5 \mathrm{gm} \%$ bile salt in normal diet and these rats were used for the experiments. Dried root powder of Asparagus racemosus was administered as feed supplement at $5 \mathrm{gm} \%$ and $10 \mathrm{gm} \%$ dose levels to the hyperlipidemic rats. Plasma lipid profile, malondialdehyde, ascorbic acid, catalase and superoxide dismutase were estimated using standard methods. Statistical analysis was done by one way analysis of variance (ANOVA).

Results: Feed supplementation with $5 \mathrm{gm} \%$ and $10 \mathrm{gm} \%$ Asparagus racemosus resulted in a significant decrease in plasma cholesterol, LDL and significant increase in HDL. But there were no significant decrease in triglycerides and VLDL. The feed supplementation increased activities of catalase, superoxide dismutase and ascorbic acid content increased significantly in both the experimental groups (5 and $10 \mathrm{gm} \%$ supplemented groups). But there was no significant change in the concentration of malondialdehyde in these groups.

Conclusions: The present study demonstrated that addition of Asparagus racemosus root powder at $5 \mathrm{gm} \%$ and $10 \mathrm{gm} \%$ level as feed supplement reduces the plasma lipid levels and also acts as an antioxidant.

Keywords: Antioxidant, Asparagus racemosus, Hyperlipidemia, Lipid profile

\section{INTRODUCTION}

Lipoprotein disorder is among the most common metabolic disease occurring in human which may lead to coronary artery disease. Excessive levels of blood cholesterol accelerate the process of atherogenesis and lowering of high blood cholesterol reduces the incidence of coronary heart disease. Knowledge about the levels of cholesterol sub-fractions is more meaningful than simple plasma cholesterol level. The higher the level of LDL cholesterol, greater is the risk of atherosclerotic heart disease and higher the level of HDL-cholesterol, lesser is the risk. ${ }^{1}$ Thus, atherosclerosis is associated with hyperlipidemia which is a major risk factor for coronary artery disease. Therefore, treatment of hyperlipidemia is one of the major approaches towards decelerating the atherogenic process. ${ }^{2,3}$

Radicals and other reactive oxygen species are formed constantly in the human body and are removed by the enzymatic and non-enzymatic antioxidant defense systems. A number of plants and plant isolates have been reported to protect free radical-induced damage in various experimental models. ${ }^{4}$ These plants with potent therapeutic components such as fibers, sterols, saponins, polyphenols, flavanoids, etc., have been investigated for their hypolipidemic and antioxidant properties. These compounds are reported to be beneficial with great 
variation in magnitude and mechanism of action and therefore have a potential therapeutic value in preventing multifactorial atherosclerotic disorders. ${ }^{5-7}$

Asparagus racemosus (AR) Willd (Family: Liliaceae), commonly known as Satawari (Hindi) is a perennial shrub. The characteristic features of the plants are a tuberous root-stock, stems covered with recurved spines, linear leaves arranged in a tuft and sweet-scented white flowers appear in October. ${ }^{8}$ Its medicinal usage has been reported in the Indian and British Pharmacopoeias and in traditional systems of medicine such as Ayurveda, Unani and Siddha. The plant has been shown to aid in the treatment of neurodegenerative disorders and in alcohol abstinence-induced withdrawal symptoms. ${ }^{9}$ Besides use in the treatment of diarrhoea and dysentery, the plant also has potent antioxidant, immunostimulant, anti-dyspepsia and antitussive effects. Due to its multiple uses, the demand for AR is constantly on the rise, but the supply is inadequate. Therefore, the need for conservation of this plant is crucial. $^{10}$

An attempt was made in the past few years to study whether AR has got any antioxidant property. Many studies revealed that $\mathrm{AR}$ possesses hypolipidemic and antioxidant potential, but results were not consistent. ${ }^{10,11}$ Therefore, the present study was undertaken to investigate lipid lowering and antioxidant potential of AR root powder in hyperlipidemic rats.

\section{METHODS}

\section{Animals}

Male albino rats weighing 200-250 gm were used for the experiment. They were kept on balanced diet and water ad libitum in a well-ventilated animal unit. The care and procedures adopted for the present investigation were in accordance with the approval of Institutional Animal Ethics Committee. Permission for conduction of study was taken from Institutional Ethics Committee.

\section{Plant Material}

Roots of Asparagus racemosus were collected from Yucca Enterprises, Wadala (E) Mumbai, India. The roots were authenticated by Professor of Botany. The roots were washed thoroughly with tap water and dried, diced into small pieces, powdered in a mixer grinder and used for the experiment.

\section{Drugs}

Cholesterol and bile salt were purchased in pure form from Yucca Enterprises, Wadala (E) Mumbai, India. 0.75 gm $\%$ cholesterol and $1.5 \mathrm{gm} \%$ bile salt of diet were used to produce hyperlipidemia in normal male albino rats. ${ }^{11}$

\section{Reagents}

Lipid profile enzymatic kits were obtained from Erba Chemicals, New Delhi. All reagents used for biochemical tests were of analytical grade.

\section{Study design}

Study was conducted as follows:

After 10 days adaptation period, 24 rats were divided into four groups, each containing six animals $(n=6)$. The groups were treated as follows for one month (four weeks):

Group I: Control group (Only standard diet is given). Group II: Standard diet mixed with $0.75 \mathrm{gm} \%$ cholesterol and $1.5 \mathrm{gm} \%$ bile salt of the weight of the total diet to induce hyperlipidemia. Group III: Standard diet mixed with $0.75 \mathrm{gm} \%$ cholesterol and $1.5 \mathrm{gm} \%$ bile salt to induce hyperlipidemia, along with 5 gm\% Asparagus racemosus root powder as feed supplement. Group IV: Standard diet mixed with $0.75 \mathrm{gm} \%$ cholesterol and 1.5 gm\% bile salt to induce hyperlipidemia, along with 10 gm\% Asparagus racemosus root powder as feed supplement.

\section{Collection of blood samples}

On $30^{\text {th }}$ day, after overnight fasting, blood was collected directly from heart of rat anaesthetized with ether. Abdomen was opened by taking a midline incision. Diaphragm was cut with precaution and blood was collected slowly from left ventricle by 24 gauge needle. Blood was sent to biochemistry laboratory in plain bulb; plasma was separated by centrifugation. Liver was excised and, both plasma and liver were kept frozen until analyzed.

\section{Biochemical analysis}

Plasma lipid profile was assessed by following parameters by standard methods: serum total cholesterol, ${ }^{12}$ serum total triglycerides (TG), ${ }^{13}$ serum total high density lipoproteins (HDL), ${ }^{14}$ serum total low density lipoproteins (LDL), ${ }^{15}$ serum total very low density lipoproteins (VLDL). ${ }^{15}$ Antioxidant potential was assessed by following parameters: Hepatic ascorbic acid, ${ }^{16}$ catalase activity in liver, ${ }^{17}$ serum malondialdehyde (MDA) ${ }^{18}$ serum superoxide dismutase activity (SOD). ${ }^{19}$

\section{Statistical Evaluation}

The results were expressed as means \pm SD (standard deviation). Significant differences among groups were determined by one way Analysis of variance (ANOVA) by using SPSS v17.0. Dunnett's test was used for post hoc test analysis. Differences were considered significant if $\mathrm{P}<0.05 .^{20}$

\section{RESULTS}

\section{Plasma lipid profile}

Asparagus racemosus (AR) root powder as $5 \mathrm{gm} \%$ feed supplementation to hyperlipidemic rats resulted in a decrease of total serum cholesterol. The cholesterol level decreased from $303.52 \pm 10.35 \mathrm{mg} \%$ to $249.53 \pm 11.25 \mathrm{mg} \%$ ( $17.82 \%$ decreased). With $10 \mathrm{gm} \%$ feed supplementation, a further reduction occurred in total serum cholesterol from $303.52 \pm 10.35 \mathrm{mg} \%$ to $225.28 \pm 8.26 \mathrm{mg} \% \quad(26.12 \%$ 
decreased). AR root powder as $5 \mathrm{gm} \%$ and $10 \mathrm{gm} \%$ feed supplementation resulted in a decrease of total serum LDL and increase in total serum HDL (Table 1). All these alterations in parameter were dose dependent and significant $(p<0.001)$.
There were no significant decrease in serum triglyceride and serum VLDL level with addition of $5 \mathrm{gm} \%$ and 10 gm\% AR feed supplementation. The values were decreased from $54.29 \pm 3.28 \mathrm{mg} \%$ to $52.33 \pm 3.99 \mathrm{mg} \%$ and from $10.86 \pm 0.66 \mathrm{mg} \%$ to $10.47 \pm 0.78 \mathrm{mg} \%$ in case of triglyceride and VLDL, respectively (Table 2).

Table 1: Effect of Asparagus racemosus root powder on serum total cholesterol, serum LDL and serum HDL level in male albino rats.

\begin{tabular}{|c|c|c|c|c|}
\hline Groups $(\boldsymbol{n = 6 )}$ & $\begin{array}{c}\text { Treatment } \\
\text { given }\end{array}$ & $\begin{array}{c}\text { Sr. TC } \\
(\mathbf{m g} / \mathbf{d l})\end{array}$ & $\begin{array}{c}\text { Sr. LDL } \\
(\mathbf{m g} / \mathbf{d l})\end{array}$ & $\begin{array}{c}\text { Sr. HDL } \\
(\mathbf{m g} / \mathbf{d l})\end{array}$ \\
\hline Group I & Control & $127.12 \pm 6.51$ & $50.04 \pm 5.41$ & $66.78 \pm 2.24$ \\
\hline Group II & HL & $303.52 \pm 10.35$ & $250 \pm 11.27$ & $42.65 \pm 1.94$ \\
\hline Group III & HL+5\%AR & $249.53 \pm 11.25^{*}$ & $187.13 \pm 13.82^{*}$ & $51.93 \pm 3.13^{*}$ \\
\hline Group IV & HL+10\%AR & $225.58 \pm 8.26^{*}$ & $159.27 \pm 9.99^{*}$ & $55.82 \pm 4.23^{*}$ \\
\hline
\end{tabular}

(All values are Mean \pm Standard Deviation). $\mathrm{HL}=$ Hyperlipidemic group, $\mathrm{HL}+5 \% \mathrm{AR}=$ Hyperlipidemic +5 gm $\%$ Asparagus racemosus root powder, $\mathrm{HL}+10 \% \mathrm{AR}=$ Hyperlipidemic +10 gm $\%$ A. racemosus root powder, $\mathrm{TC}=\mathrm{Total}$ Cholesterol, $\mathrm{LDL}=$ low density lipoproteins, $\mathrm{HDL}=$ high density lipoproteins, ${ }^{*} p<0.001$ compared to Group II (ANOVA followed by Dunnett's test).

Table 2: Effect of Asparagus racemosus root powder on serum TG and serum VLDL level in male albino rats.

\begin{tabular}{|c|c|c|c|}
\hline $\begin{array}{c}\text { Groups } \\
(\boldsymbol{n}=\mathbf{6})\end{array}$ & $\begin{array}{c}\text { Treatment } \\
\text { given }\end{array}$ & $\begin{array}{c}\text { Sr. TG } \\
(\mathbf{m g} / \mathbf{d l})\end{array}$ & $\begin{array}{c}\text { Sr. VLDL } \\
(\mathbf{m g} / \mathbf{d l})\end{array}$ \\
\hline Group I & Control & $51.53 \pm 2.75$ & $10.31 \pm 0.55$ \\
\hline Group II & HL & $54.29 \pm 3.28$ & $10.86 \pm 0.66$ \\
\hline Group III & HL+5\%AR & $52.33 \pm 3.99_{\mathrm{NS}}$ & $10.47 \pm 0.78_{\mathrm{NS}}$ \\
\hline Group IV & HL+10\%AR & $52.48 \pm 4.26_{\mathrm{NS}}$ & $10.49 \pm 0.85_{\mathrm{NS}}$ \\
\hline
\end{tabular}

(All values are Mean \pm Standard Deviation). $\mathrm{HL}=$ Hyperlipidemic group, $\mathrm{HL}+5 \% \mathrm{AR}=$ Hyperlipidemic +5 gm $\%$ Asparagus racemosus root powder, $\mathrm{HL}+10 \% \mathrm{AR}=$ Hyperlipidemic $+10 \mathrm{gm} \%$ A. racemosus root powder, $\mathrm{TG}=\mathrm{Total}$ triglycerides, VLDL = very low density lipoproteins, NS - Non-significant compared to Group II (ANOVA followed by Dunnett's test).

Table 3: Effect of Asparagus racemosus root powder on total ascorbic acid and activities of catalase in liver of male albino rats.

\begin{tabular}{|c|c|c|c|}
\hline Groups $(\boldsymbol{n}=\mathbf{6})$ & $\begin{array}{c}\text { Treatment } \\
\text { given }\end{array}$ & Total ascorbic acid $(\boldsymbol{\mu} / \mathbf{g})$ & $\begin{array}{c}\text { Catalase } \mathbf{~} \mathbf{m m} \mathbf{H}_{\mathbf{2}} \mathbf{O}_{\mathbf{2}} \\
\text { decomposed/sec/gm }\end{array}$ \\
\hline Group I & Control & $56.53 \pm 2.75$ & $20.31 \pm 0.55$ \\
\hline Group II & HL & $44.29 \pm 3.28$ & $13.86 \pm 0.66$ \\
\hline Group III & HL+5\%AR & $52.33 \pm 3.99 *$ & $14.47 \pm 0.78^{*}$ \\
\hline Group IV & HL+10\%AR & $52.48 \pm 4.26^{*}$ & $14.49 \pm 0.85^{*}$ \\
\hline
\end{tabular}

(All values are Mean \pm Standard Deviation). HL = Hyperlipidemic group, $\mathrm{HL}+5 \%$ AR $=$ Hyperlipidemic +5 gm $\%$ Asparagus racemosus root powder, $\mathrm{HL}+10 \% \mathrm{AR}=$ Hyperlipidemic +10 gm $\%$ A. racemosus root powder, $* p<0.05$ compared to Group II (ANOVA followed by Dunnett's test). 
Table 4: Effect of Asparagus racemosus root powder on serum MDA and serum SOD level in male albino rats.

\begin{tabular}{|c|c|c|c|}
\hline Groups $(\boldsymbol{n = 6})$ & Treatment given & Sr. MDA $(\mathbf{n m o l} / \mathbf{m l})$ & Sr. SOD $(\mathbf{U} / \mathbf{m l})$ \\
\hline Group I & Control & $1.41 \pm 0.27$ & $11.93 \pm 0.64$ \\
\hline Group II & HL & $3.47 \pm 0.40$ & $5.78 \pm 0.73$ \\
\hline Group III & HL+5\%AR & $3.03 \pm 0.33_{\mathrm{NS}}$ & $7.55 \pm 0.99 *$ \\
\hline Group IV & HL+10\%AR & $2.91 \pm 0.61_{\mathrm{NS}}$ & $8.37 \pm 0.71^{*}$ \\
\hline
\end{tabular}

(All values are Mean \pm Standard Deviation). $\mathrm{HL}=$ Hyperlipidemic group, $\mathrm{HL}+5 \% \mathrm{AR}=$ Hyperlipidemic +5 gm $\%$ Asparagus racemosus root powder, $\mathrm{HL}+10 \% \mathrm{AR}=\mathrm{Hyperlipidemic}+10 \mathrm{gm} \% \mathrm{~A}$. racemosus root powder, $\mathrm{MDA}=$ Malondialdehyde, $\mathrm{SOD}=$ Superoxide dismutase. NS $=$ Non significant compared to Group II, $* p<0.05$ compared to Group II (ANOVA followed by Dunnett's test).

\begin{abstract}
Antioxidant potential
Total ascorbic acid and catalase activity in liver were increased from $44.29 \pm 3.28$ to $52.33 \pm 3.99 \mu / \mathrm{g}$ and 13.86 \pm 0.66 to $14.47 \pm 0.78 \mathrm{~nm}$ respectively in $5 \mathrm{gm} \% \mathrm{AR}$ treated rats. But there were no further reduction in 10 gm\% AR treated rats (Table 3).
\end{abstract}

The lipid peroxidation product, malondialdehyde, in serum decreased in AR root powder treated groups as compared to hyperlipidemic group i.e. from $3.47 \pm 0.40$ $\mathrm{nmol} / \mathrm{ml}$ to $3.03 \pm 0.33 \mathrm{nmol} / \mathrm{ml}$ and from $3.47 \pm 0.40$ $\mathrm{nmol} / \mathrm{ml}$ to $2.91 \pm 0.61 \mathrm{nmol} / \mathrm{ml}$ in respectively $5 \mathrm{gm} \%$ and $10 \mathrm{gm} \%$ AR treated groups (Table 4). But these reductions were not dose dependent. Also these reductions were not statistically significant.

The activity of superoxide dismutase increased in both experimental AR root powder treated groups as compared to hyperlipidemic group i.e. from $5.78 \pm 0.73 \mathrm{U} / \mathrm{ml}$ to $7.55 \pm 0.99 \mathrm{U} / \mathrm{ml}$ and from $5.78 \pm 0.73 \mathrm{U} / \mathrm{ml}$ to $8.37 \pm 0.71$ $\mathrm{U} / \mathrm{ml}$ respectively (Table 4). These increases in superoxide dismutase activity were dose dependent and statistically significant $(p<0.05)$.

\section{DISCUSSION}

The present study was conducted on male albino rats to assess the lipid lowering and antioxidant activities of Asparagus racemosus (AR) root powder. Various biochemical parameters like serum total cholesterol, triglycerides (TG), low density lipoproteins (LDL), high density lipoproteins (HDL) and very low density lipoproteins (VLDL) were used to assess the hypolipidemic activities. For antioxidant activity, parameters like catalase, superoxide dismutase, ascorbic acid, malondialdehyde, uric acid etc. could be studied. But, in this study only ascorbic acid, catalase, superoxide dismutase and malondialdehyde were studied as reagents for others were not available. Addition of AR dried root powder as a feed supplement at two levels, i.e. $5 \mathrm{gm} \%$ and $10 \mathrm{gm} \%$ resulted in a significant and dose dependent reduction in lipid profile in plasma. The lipid-lowering effects of AR root powder in hyperlipidemic rats demonstrated in the present investigation were related primarily to a decreased level of total serum cholesterol and LDL-cholesterol level while increase in HDLcholesterol level. There was no significant decrease in serum triglycerides as well as VLDL.

Visavadiya and Narasimhacharya ${ }^{11}$ studied the efficacy of Asparagus racemosus in reducing the cholesterol levels and as an antioxidant in hyperlipidemic rats. The study demonstrated that addition of Asparagus racemosus root powder at $5 \mathrm{gm} \%$ and $10 \mathrm{gm} \%$ level as feed supplement reduced the plasma lipid profile including serum triglycerides as well as VLDL. In another study by same author, there were no significant changes in TG and VLDL. ${ }^{10}$ In this study, the phytosterol $(0.79 \mathrm{gm} \%)$ and saponin (8.83 gm\%) contents of AR root (besides polyphenols, $1.69 \mathrm{gm} \%$; flavonoids, $0.47 \mathrm{gm} \%$ ascorbic acid, $0.76 \mathrm{gm} \%$ ) could be responsible for decreased cholesterol levels in the hyperlipidemic rats. Phytosterols compete and displace cholesterol from the intestinal bile acid micelles and in this way decrease the cholesterol circulation. $^{21,22}$ Saponins precipitate cholesterol from micelles and interfere with entero-hepatic circulation of bile acids. Thus, saponins also reduce plasma cholesterol levels by inhibiting its absorption. ${ }^{23,24}$

It is well known that while a low level of HDL-C is indicative of high risk for cardiovascular disease, an increase in HDL-C level could potentially contribute to reversal of atherogenesis. This is because high level of HDL-C protects endothelial cells from the cytotoxic effects of oxidized LDL. ${ }^{25}$ In the present study, a significant increase in plasma HDL-C levels with a simultaneous lowering in plasma cholesterol level definitely indicate the beneficial role of $\mathrm{AR}$ root administration to hyperlipidemic animals.

The present study showed significant increase in levels of serum malondialdehyde (MDA) and significant decrease in levels of superoxide dismutase (SOD) in hyperlipidemic group. Hyperlipidemic condition leads to disturbances in circulation and oxygenation which in turn 
cause lipid peroxidation and subsequently increase MDA concentration. Therefore, lipid peroxidation may cause severe damage and play a key role in pathogenesis of several human diseases. Superoxide dismutase is an antioxidant enzyme which can destroy the superoxide anion $\left(\mathrm{O}^{-}\right)$. This decrease in SOD activity could be due to the increased production of reactive oxygen species as evident from the increased lipid peroxidation levels due to hypercholesteremia. An increased production of free radicals such as superoxide anions and metabolites and a reduced bioavailability of antioxidants cause oxidative damage to cells and tissues. An imbalance between prooxidant and antioxidant levels in the body gives rise to cellular oxidative stress that plays an important role in the genesis of cardiovascular diseases. ${ }^{26-29}$ Cholesterol- rich diets increase both LDL-C levels and oxidative stress and result in increased oxidized LDL levels which are responsible for atherosclerotic plaque formation. ${ }^{30}$ In present study, there was significant increase in serum SOD in AR treated groups which show antioxidant potential of the plant. There was no significant decrease in serum MDA. In 2005, in one study, there were significant changes in both SOD and MDA parameters, but changes were not dose dependent. ${ }^{11}$

Several past studies suggest that naturally occurring antioxidants such as polyphenols, flavonoids and ascorbic acid in diet may play an important role in prevention of atherosclerosis process. These antioxidants are known to scavenge different types of free radicals, inhibit lipid peroxidation and improve lipid profiles. These antioxidants also stimulate catalase and superoxide dismutase enzyme activity and decrease malondialdehyde concentration. Several past evidences suggest that ascorbic acid is a powerful antioxidant in biological systems as an electron donor. It prevents cellular oxidative damage by scavenging the reactive oxygen and nitrogen species. ${ }^{10}$

Presently noted lower levels of MDA and higher levels of SOD activities in AR root powder treated groups (Group III \& Group IV) indicate the possible role of antioxidants of AR root such as polyphenols and flavonoids, in modifying the expression of both lipid peroxidase and superoxide dismutase activities, respectively. In past, many studies were conducted with AR extract to confirm its antioxidant activity although the principles responsible for this activity were not reported. ${ }^{31-37}$ Taken together, these observations indicate that Asparagus racemosus root powder administration to hyperlipidemic animals can reduce serum lipid levels and modulate antioxidant enzyme activities.

There were certain drawbacks of this study. Varied chemical composition of AR roots makes it difficult to assign its hypolipidemic and antioxidant properties to one of its constituent. Therefore, more detailed experimental and then clinical studies are required with different isolated compounds present in $\mathrm{AR}$ root to confirm its hypolipidemic action in hyperlipidemic conditions.
Thus, we conclude that Asparagus racemosus root powder administration could decrease plasma lipids and oxidative stress in hyperlipidemic conditions which were produced by administration of cholesterol and bile salt in diet.

\section{ACKNOWLEDGEMENTS}

We are thankful to Dr. V. V. Wase, Dean, S. R. T. R. Govt. Medical College, Ambajogai, for allowing us to carry out this study.

Funding: No funding sources

Competing interest: None declared

Ethical approval: Permission of Institutional Animal

Ethics Committee was taken

\section{REFERENCES}

1. Ajayi OB, Ajayi DD. Effect of oilseed diets on plasma lipid profile in albino rats. Pak J Nutr 2009;8:116-8.

2. Kothari S, Jain AK, Mehta SC, Tonpay SD. Effect of fresh Triticum aestivum grass juice on lipid profile of normal rats. Indian $\mathbf{J}$ Pharmacol 2008;40:235-6.

3. Sandeep S, Koneri R, Mushirbhai MI. Evaluation of antihyperlipidimic activity of saponin fraction of roots of Memordica cymbalaria. Indian J Pharmacol 2008;40 (Suppl 2):S221-S236.

4. Sundaram R, Mitra SK. Antioxidant activity of ethyl acetate soluble fraction of Acacia arabica bark in rats. Indian J Pharmacol 2007;39:33-8.

5. Lindequist U, Niedermeyer THJ, Julich WD. The pharmacological potential of mushrooms. Evid Based Complement Alternat Med 2005;2:285-99.

6. Nozaki K, Hikiami H, Goto $H$, Nakagawa $T$, Shibahara N, Shimada Y. Keishibukuryogan (GuiZhi-Fu-Ling-Wan), a kampo formula, decreases disease activity and soluble vascular adhesion molecule-1 in patients with rheumatoid arthritis. Evid Based Complement Alternat Med 2006;3:35964.

7. Venkatesan N, Devaraj SN, Devaraj H. Increased binding of LDL and VLDL to apo B,E receptors of hepatic plasma membrane of rats treated with fibernat. Eur J Nutr 2003;42:262-71.

8. Venkatesan N, Thiyagarajan V, Narayanan S, Arul A, Raja S, et al. Anti-diarrhoeal potential of Asparagus racemosus wild root extracts in laboratory animals. J Pharm Pharm Sci 2005;8:3946.

9. Bopana N, Saxena S. Asparagus racemosus--ethno pharmacological evaluation and conservation needs. J Ethnopharmacol 2007;110:1-15.

10. Visavadiya NP, Narsimhacharya AVRL. Asparagus racemosus regulates Cholesterol metabolism and Improves antioxidant status in Hyperlipidemic rats. Evid Based Complement Alternat Med 2009;6:21926. 
11. Visavadiya NP, Narsimhacharya AV. Hypolipidemic and antioxidant activities of Asparagus racemosus in Hyperlipidemic rats. Indian J Pharmacol 2005;37:376-80.

12. Roeschlau P, Bernt E, Gruber W. Enzymatic determination of total cholesterol in serum. Z Klin Chem Klin Biochem 1974;12:226.

13. McGowan MW, Artiss JD, Strandbergh DR, Zak B. A peroxidase-coupled method for the colorimetric determination of serum triglycerides. Clin Chem 1983;29:538-42.

14. Lorentz K, Flatter B, Augustin E. Arylesterase in serum: Elaboration and clinical application of a fixed incubation period. Clin Chem 1979;25:171420.

15. Chatterjee MN. Textbook of Medical Biochemistry, $7^{\text {th }}$ edition. JAYPEE Brothers: New Deli, India 2007;418-20.

16. Schaffert RR, Kingsley GR. A rapid, simple method for the determination of reduced, dehydro-, and total ascorbic acid in biological material. $\mathrm{J}$ Biol Chem1955;212:59-68.

17. Cohen G, Dembiec D, Marcus J. Measurement of catalase activity in tissue extracts. Anal Biochem1970;34:30-8.

18. Pasha KV, Sadasivadu B. Intracellular content of thiol compounds, thiobarbituric acid reactive substances and gamma-glutamyl transpeptidase in rat brain during anoxia. Neurosci Lett 1984;46:20914.

19. Marklund S, Marklund G. Involvement of the superoxide anion radical in the autoxidation of pyrogallol and a convenient assay for superoxide dismutase. Eur J Biochem 1974;47:469-74.

20. Mahajan BK. Significance of difference in means. In: Mahajan BK (ed) Methods in biostatistics for medical and research workers. 6th ed. New Delhi: JAYPEE Brothers Medical Publishers, 2006:130-55.

21. Ikeda I, Sugano M. Inhibition of cholesterol absorption by plant sterols for mass intervention. Curr Opin Lipidol 1998;9:527-31.

22. Quilez J, Garcia-Lorda P, Salas-Salvado J. Potential uses and benefits of phytosterols in diet: present situation and future directions. Clin Nutr 2003;22:343-51.

23. Harwood HJ Jr, Chandler CE, Pellarin LD, Bangerter FW, Wilkins RW, Long CA, et al. Pharmacologic consequences of cholesterol absorption inhibition: alteration in cholesterol metabolism and reduction in plasma cholesterol concentration induced by the synthetic saponin $\beta$ tigogenin cellobioside (CP-88818; tiqueside). J Lipid Res 1993;34:377-95.
24. Oakenfull DG, Sidhu GS. Could saponins be a useful treatment for hypercholesterolaemia? Eur $\mathrm{J}$ Clin Nutr 1990;44:79-88.

25. Assmann G, Nofer J. Atheroprotective effects of high density lipoproteins. Annu Rev Med 2003;54:321-41.

26. Young IS, Woodside JV. Antioxidants in health and diseases. J Clin Pathol 2001;54:176-86.

27. Block G, Dietrich M, Norkus EP, Morrow JD, Hudes M, Caan B, Packer L. Factors sssociated with oxidative stress in human populations. Am J Epidemiol 2002;156:274-85.

28. Bagchi K. Nutrition in the Eastern Mediterranean Region of the World Health Organization. East Mediterr Health J 2008;14 Suppl:S107-13.

29. Tiwari AK. Imbalance in antioxidant defence and human diseases: multiple approach of natural antioxidants therapy. Curr Sci 2001;81:1179-80.

30. Barter P, Gotto AM, LaRosa JC, Maroni J, Szarek M, Grundy SM, Kastelein JJ, et al. HDL cholesterol, very low levels of LDL cholesterol, and cardiovascular events. N Engl J Med 2007;357:1301-10.

31. Ramakrishnan V, Gopala Reddy A, Kalakumar B. Antioxidant actions of Asparagus racemosus against iron induced oxidative stress in broilers. Indian $\mathbf{J}$ Pharmacol 2008;40(Suppl 2):S160-S171.

32. Visavadiya NP, Soni B, Soni B, Madamwar D. Suppression of reactive oxygen species and nitric oxide by Asparagus racemosus root extract using in vitro studies. Cell Mol Biol (Noisy-le-grand) 2009;55 Suppl:OL1083-95.

33. Muralidharan P, Nandagopal M. Cerebroprotective effect of methanolic extract of Asparagus racemosus in cerebral ischemia induced by bilateral carotid artery occlusion in rats. Indian J Pharmacol 2008;40(Suppl 2):S112-S142.

34. Wiboonpun N, Phuwapraisirisan P, Tip-pyang S. Identification of antioxidant compound from Asparagus racemosus. Phytother Res 2004;18:7713.

35. Parihar MS, Hemnani T. Experimental excitotoxicity provokes oxidative damage in mice brain and attenuation by extract of Asparagus racemosus. J Neural Transm 2004;111:1-12.

36. Kamat JP, Boloor KK, Devasagayam TP, Venkatachalam SR. Antioxidant properties of Asparagus racemosus against damage induced by gamma-radiation in rat liver mitochondria. $\mathbf{J}$ Ethnopharmacol 2000;71:425-35.

37. Bhatnagar M, Sisodiya SS, Bhatnagar R. Antiulcer and antioxidant Activity of Asparagus racemosus Willd and Withania somnifera Dunal in rats. Ann N Y Acad Sci 2005;1056:261-78.

doi: 10.5455/2319-2003.ijbcp003112

Cite this article as: Bhosale RR, Jaju JB, Padwal SL, Jadhav RR, Deshmukh VS. Lipid lowering and antioxidant potential of Asparagus racemosus in hyperlipidemic rats. Int J Basic Clin Pharmacol 2012; $1: 168-73$. 